\title{
AN ATYPICAL PRESENTATION OF GROWING SKULL FRACTURE: A CASE REPORT
}

Ashok Nayak ${ }^{1}$, Satyadeo Sharma², Rohan S. Batra3 ${ }^{3}$, Rakesh Kumar Vadher ${ }^{4}$, Sourabh Dixit ${ }^{5}$

\section{HOW TO CITE THIS ARTICLE:}

Ashok Nayak, Satyadeo Sharma, Rohan S. Batra, Rakesh Kumar Vadher, Sourabh Dixit. "An Atypical Presentation of Growing Skull Fracture: A Case Report". Journal of Evolution of Medical and Dental Sciences 2015; Vol. 4, Issue 30, April 13; Page: 5251-5256, DOI: 10.14260/jemds/2015/769

ABSTRACT: A growing skull fracture (GSF) or craniocerebral erosion or leptomeningeal cyst, is characterized by progressive diastatic enlargement of fracture line. Growing skull fracture is a rare neurological complication and accounts for $1.2-1.6 \%$ of the head injury patients. GSF is generally seen in children less than 3 year of age. Authors present an atypical case of growing skull fracture in comminuted type of skull fracture which was timely and successfully managed with very good outcome. Atypical presentation, risk factors, etiopathogenesis, management and outcome in GSF is discussed along with review of literature. Delayed diagnosis and improper treatment could worsen this condition while timely surgical intervention can have excellent outcome.

KEYWORDS: Growing skull fracture, craniocerebral erosion, Childhood skull fracture, Leptomeningeal cyst.

ABBREVIATIONS: GSF: Growing skull fracture, GCS-Glasgow Coma Score.

INTRODUCTION: A growing skull fracture (GSF) is also known as Leptomeningeal cyst, due to development of a cystic mass lesion filled with cerebrospinal fluid. Skull fracture enlarges due to rapid physiological growth of brain and CSF pulsations in the leptomeningeal mass underlying dural tear. Growing fractures progressively increase in size and may be associated with an underlying dural tear and arachnoid cyst formation. In the background of increasing pediatric head injuries especially in present scenario, likelihood of GSF cannot be underestimated.

CASE REPORT: Authors describe a case of 12 month old female baby who presented with history of accidental fall of an electric pole over her head followed by unconsciousness and convulsions. There was palpable swelling over right side of scalp and a bony gap could also be appreciated. Patient was initially resuscitated, stabilized and thoroughly investigated. Patient was anemic, malnourished with presenting Glasgow coma score (GCS) of 5/15, so she was managed conservatively initially till her condition stabilized. Her CT SCAN (Figure 1, 2, 3) showed following findings.

CT-SCAN study reveals fracture of right fronto-parietal bone and temporal bone with displacement of fracture fragments. There is fracture of right petrous temporal bone. There was moderate diffuse cerebral edema and tectorial bleed. Multifocal hemorrhagic contusions in right frontoparietal and right temporal lobe with surrounding perilesional edema, subarachnoid bleed in right sylvian fissure and in sulcal spaces at right frontoparietal region.

She was managed conservatively initially, her general condition gradually improved. Her level of consciousness (GCS 12/15) also improved but scalp swelling and bony gap kept on increasing. Surgical intervention was planned with aim to explore the wound in its extent, manage bony injury, dural defect and contusion injury of the brain tissue accordingly. 


\section{CASE REPORT}

Surgical Findings: On making the scalp incision, gush of fluid, CSF, blood stains along with contused brain matter filling the subcutaneous area of scalp came out (Figure 4,5). A big bony gap was noted in right frontoparietal region of scalp. There was $1 \mathrm{~cm}$ to $4 \mathrm{~cm}$ gap along with free bony fragments in the gap. On removing the bony fragments dural edges could not be defined as it was retracted underneath the bone. Some nibbling of healthy bone was required to define the duramater edges on both the sides. Assessment of dural gap was done and accordingly fascia lata from right thigh was taken. The most important step of surgery is water-tight closure of the dural defect, as described in previous studies.1,2,3,4 Duroplasty was done as shown (figure 6). Patient showed gradual good recovery in general condition and neurological symptoms. Left sided limb weakness improved from grade 1 to grade 3.Patient become fully conscious except left $6^{\text {th }}$ nerve paresis. Post-operative recovery was uneventful. Patient had 3 regular monthly follow-up and showed continuous recovery in motor as well as neurological symptoms, however left $6^{\text {th }}$ nerve palsy still persists (Figure 7).

DISCUSSION: In 1816, John Hopkins described an infant with GSF following head trauma. Since then, cases of GSF continue to appear in the literature under varied terminologies like leptomeningeal cyst, traumatic meningocoele, cerebrocranial erosion, cephalohydrocoele, meningocoele spuria, etc.4,6,7 The exact etiopathological process of growing skull fracture is unclear. The single most important factor in the pathogenesis of growing skull fracture is dural tear. $., 8,9$

In 1961, Lende and Erickson reviewed the literature on this subject and emphasised on four essential features:

1. Skull fracture in infancy or early childhood;

2. Dural tear at the time of fracture;

3. Brain injury underlying the fracture; and

4. Subsequent enlargement of the fracture resulting in a cranial defect ${ }^{10}$. Combination of these factors alters the normal distribution of intracranial pressure and the bony defect acts like a neosuture through which the dura along with brain herniates. Growing skull fracture commonly involves the calvarial bones.

The typical patient with a growing skull fracture is younger than 3 years, has a subgaleal fluid collection overlying the fracture, has a neurological deficit caused by the injury and has skull radiographs that demonstrate a diastatic linear fracture with at least 3.5-mm separation of the bone edges $^{5}$. Etiology of GSF is multifactorial but the predominant factor in their causation is the presence of lacerated dura mater.11,12 The pulsatile force of the brain during its maximum growth will cause cerebral or subarachnoid herniation through the lacerated dura which causes the fracture in the thin skull to enlarge. This interposition of tissue prevents osteoblasts from migrating, inhibiting fracture healing. The resorption of the adjacent bone by the continuous pressure from tissue herniation through the bone gap adds to the progression of the fracture line.

Our patient differ from usual cases in terms of comminuted type of fracture, involvement of a large area (Fronto-temporo-pareital), extensive dural defect, rupture of leptomeningeal cyst and spillage of CSF along with contused brain underneath the galea aponeurotica. 


\section{CASE REPORT}

CONCLUSION: Presentation, outcome and long term recovery in a case of child are significantly different from adults. A child has better neurological recovery power than adults. There is significant bony reunion and remodeling capacity in children. With timely surgical intervention by watertight duroplasty GSF was successfully managed with very good outcome.

\section{REFERENCES:}

1. Diyora B, Nayak N, Kamble H, Kukreja S, Gupte G, Sharma A. Surgical treatment and results in growing skull fracture. Neurol India 2011; 59: 424-8.

2. Parmar RC, Bavdekar SB. Images in radiology: Type III growing skull fracture. J Postgrad Med 2000; 46: 130-1.

3. Pezzotta S, Silvani V, Gaetani P, et al: Growing skull fractures of childhood. Case report and review of 132 cases. J Neurosurg Sci 1985; 29:129-135.

4. Tandon PN, Banerji AK, Bhatia R, et al: Cranio-cerebral erosion (growing fracture of the skull in children). Part II. Clinical and radiological observations. Acta Neurochir (Wien) 1987; 88: 1-9.

5. Naim-Ur-Rahman, Jamjoom Z, Jamjoom A, Murshid WR. Growing skull fractures: Classification and management. Br J Neurosurg 1994; 8: 667-79.

6. Roy S, Sarkar C, Tandon PN, et al: Cranio-cerebral erosion (growing fracture of the skull in children). Part I. Pathology. Acta Neurochir (Wien) 1987; 87:112-118.

7. Taveras JM, Ransohoff J: Leptomeningeal cysts of the brain following trauma with erosion of the skull. A study of seven cases treated by surgery. J Neurosurg 1953; 10:233-241.

8. Arseni C, Ciurea AV: Clinicotherapeutic aspects in the growing skull fracture. A review of the literature. Childs Brain 1981; 8:161-172.

9. Muhonen MG, Piper JG, Menezes AH: Pathogenesis and treatment of growing skull fractures. Surg Neurol 1995; 43:367-372.

10. Lende RA, Erickson TC. Growing skull fractures of childhood. J Neurosurg 1961; 18: 479-89.

11. Vignes JR, Jeelani NU, Jeelani A, Dautheribes M, Liguoro D. Growing skull fracture after minor closed-head injury. J Pediatr 2007; 151: 316-318.

12. Wang X, Li G, Li Q, You C. Early diagnosis and treatment of growing skull fracture. Neurol India 2013; 61: 497-500. 


\section{CASE REPORT}

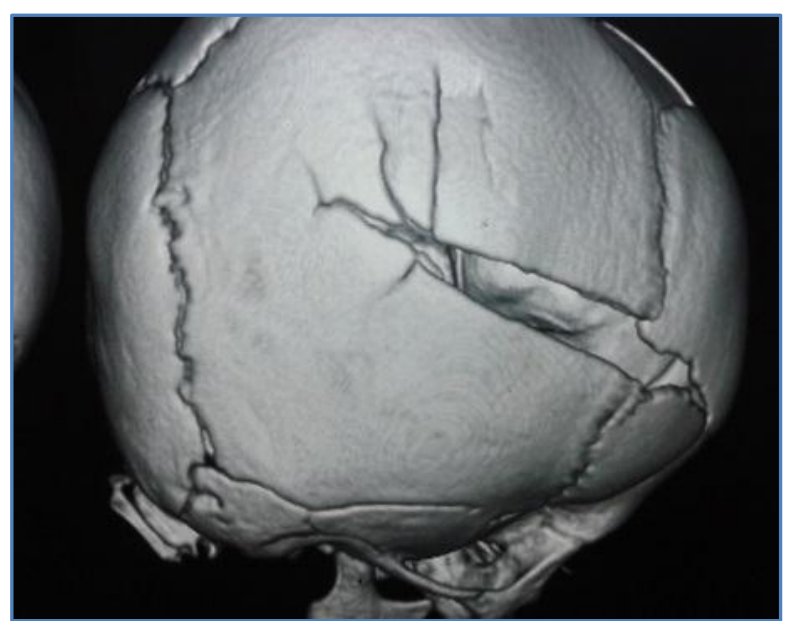

Image 1: Showing CT Scan image of the bony defect and displacement

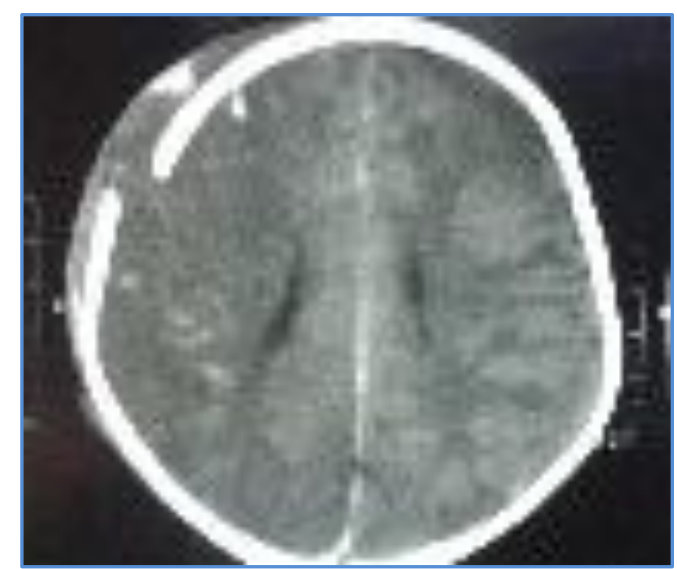

Image 2: Showing section of the CT

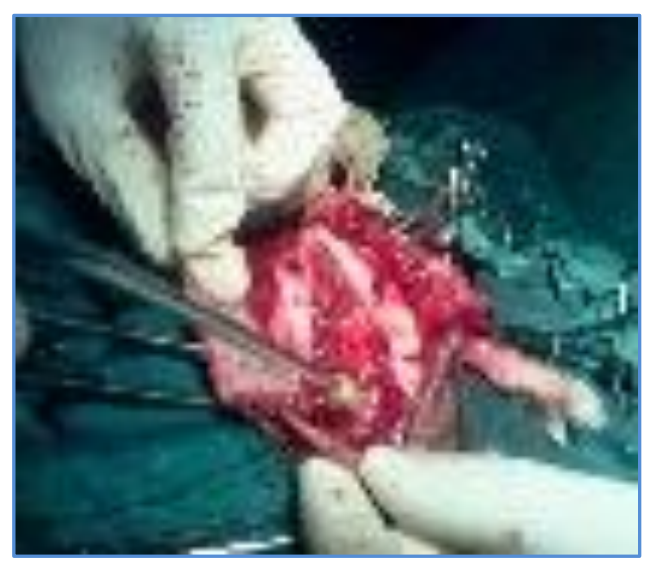

Image 3: Showing the dural defect being delineated and covered by fascia graft 


\section{CASE REPORT}

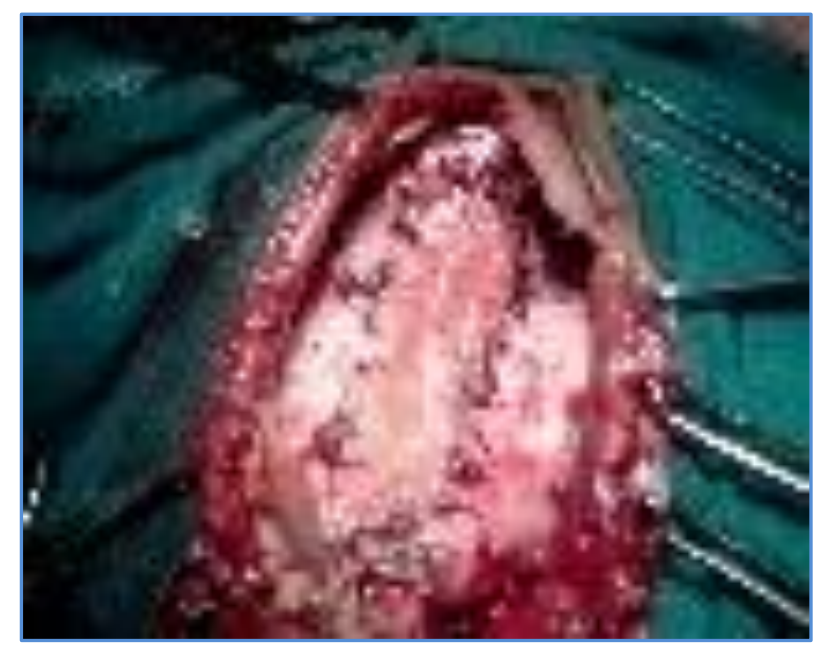

Image 4: Showing the completed duroplasty



Image no. 5: Showing the residual sixth cranial nerve paresis at post-operative follow up 


\section{AUTHORS:}

1. Ashok Nayak

2. Satyadeo Sharma

3. Rohan S. Batra

4. Rakesh Kumar Vadher

5. Sourabh Dixit

\section{PARTICULARS OF CONTRIBUTORS:}

1. Assistant Professor, Department of Surgery, Shyam Shah Medical College and Sanjay Gandhi Hospital, Rewa, M. P, India.

2. $3^{\text {rd }}$ Year Resident, Department of Surgery, Shyam Shah Medical College and Sanjay Gandhi Hospital, Rewa, M. P, India.

3. $3^{\text {rd }}$ Year Resident, Department of Surgery, Shyam Shah Medical College and Sanjay Gandhi Hospital, Rewa, M. P, India.

FINANCIAL OR OTHER COMPETING INTERESTS: None
4. $3^{\text {rd }}$ Year Resident, Department of Surgery, Shyam Shah Medical College and Sanjay Gandhi Hospital, Rewa, M. P, India.

5. $3^{\text {rd }}$ Year Resident, Department of Surgery, Shyam Shah Medical College and Sanjay Gandhi Hospital, Rewa, M. P, India.

\section{NAME ADDRESS EMAIL ID OF THE CORRESPONDING AUTHOR:}

Dr. Satyadeo Sharma,

Room No. 20, Boys Hostel,

Sanjay Gandhi Memorial Hospital,

Rewa-486001, Madhya Pradesh, India.

E-mail: satyadeo2004@gmail.com

Date of Submission: 17/03/2015.

Date of Peer Review: 18/03/2015.

Date of Acceptance: 31/03/2015.

Date of Publishing: 13/04/2015. 